Available online on 15.03 .2017 at http://jddtonline.info
o 2011-17, publisher and licensee JDDT, This is an Open Access article which permits unrestricted
noncommercial use, provided the original work is properly cited

Research Article

\title{
HYPOGLYCEMIC POTENTIAL OF PROBIOTIC DNA LOADED CHITOSAN NANOPARTICLES: AN IN VIVO STUDY
}

\author{
Kaur Manpreet*1, Bhatia Aruna ${ }^{2}$, Sethi Dimple ${ }^{3}$, Kaur Gurpreet ${ }^{4}$, Vig Kajol ${ }^{5}$ \\ ${ }_{1,2,45}^{1}$ Immunology \& Immunotechnology lab, Department of Biotechnology, Punjabi University, Patiala \\ ${ }^{3}$ Department of Pharmaceutical Sciences \& Drug research, Punjabi University, Patiala
}

\section{ABSTRACT}

The rise in infectious diseases as well as noninfectious immune related disorders causes millions of premature deaths worldwide and demands the need for the development of efficient immunomodulators. Consumer awareness about the harmful effects of chemical drugs raised a need to search for natural / alternative therapies for the treatment of diseases. Immunotherapy is one of the alternative ways of modification of diseases. Some bacterial cell components such as peptidoglycans, lipoteichoic acid, secreted soluble substances, genomic DNA, etc, play role in immunomodulation responses. Structural difference between bacterial and eukaryotic DNA apparently account for the ability of bacterial DNA to serve as an immune activating agent, because of its high content of unmethylated CpG dinucleotides. Probiotic DNA's efficacy could be further enhanced by loading it onto nanoparticles. Nanoparticle-assisted delivery may be a promising approach to alleviate the problem of instability and degradation of DNA. The present study was conducted to prepare and characterize the probiotic DNA loaded chitosan nanoparticles (DLCNP) and to find out the anti-diabetic potential of probiotic bacterial DNA Lactobacillus acidophilus NCDC 343 (LA DNA). Therapeutic efficacy of Probiotic DNA loaded with Chitosan Nanoparticles was evaluated in treating diabetic Balb/c mice. DNA loaded Chitosan Nanoparticles proved as effective anti-diabetic agents and in addition, the bioactivity of probiotic DNA was improved through nano delivery.

Keywords: Probiotics, Probiotic DNA, Chitosan-DNA Nanoparticles, Immunotherapy, Anti-diabetic/ Hypoglycemic activity

Article Info

Received Feb 02, 2017; Review Completed March 06, 2017; Accepted March 12, 2017; Available online March 15, 2017

Cite this article as:

Kaur M, Bhatia A, Sethi D, Kaur G, Vig K, Hypoglycemic potential of probiotic dna loaded chitosan nanoparticles: an in vivo study, Journal of Drug Delivery and Therapeutics. 2017; 7(2):70-76. DOI: http://dx.doi.org/10.22270/jddt.v7i2.1405

*Address for Correspondence

Kaur Manpreet, Immunology \& Immunotechnology lab, Department of Biotechnology, Punjabi University, Patiala Email: manpreet.manuksaini@gmail.com

\section{INTRODUCTION}

An inactive life, which involves lack of exercise \& poor calorie management, is one of the biggest contributors to the dreaded disease of diabetes. India is facing an epidemic of diabetes. At present confirmed diabetes patients in India are 62 million, with another 30 million pre-diabetes group. By 2030, diabetes mellitus may afflict up to 79.4 million individuals in India ${ }^{1}$. Diabetes is not only a blood sugar problem, but brings along other complications as well.
Diabetes can be treated by chemicals or drugs e.g. Pramlintide such as (SymlinPen 120, SymlinPen 60). But these drugs have various side effects also such as nausea ${ }^{2}$, vomiting, and watery diarrhea, headache and indigestion, mild allergic reactions with rash, itchiness and fever, problems with the kidneys, liver, lungs and pancreas. But due to their various side effects and consumer awareness, people are moving towards natural and safe means for treating the diseases. 
Immunotherapy using probiotics could be one of the safe strategies for treating diabetes. As probiotics are proved immunomodulators and have been given a GRAS status (Generally Regarded As Safe), hence the immunomodulation through probiotics has been selected for the study. Probiotics are important for the development as well as maintenance of innate and adaptive immunity, digestive and metabolic actions, and discourage the colonization of pathogens ${ }^{3}$. Probiotics have been emerging as important alternatives for the replacement of these food additives ${ }^{4,5}$.

Prokaryotic cell components consist of peptidoglycans, lipo-teichoic acid, some other secreted soluble substances and genomic DNA which can act as immunomodulatory agents. The probiotic genomic DNA as also proved to be immunomodulatory ${ }^{6,7}$. Prokaryotic DNA when enters the eukaryotic cells, serves as immune-modulator or immune activating agent. Short sequences with unmethylated $\mathrm{CpG}$ dinucleotides present in the bacterial DNA are responsible for the immune-modulatory changes. Oligodeoxynucleotides (ODN) containing $\mathrm{CpG}$ motifs activate the host defense mechanisms which lead to the innate and acquired immune responses. As the naked DNA is degraded in the body systems because of the presence of nucleases in the serum, hence the availability of DNA into the cells of body, reduces, due to which it needs to be loaded onto different materials ${ }^{8}$.

Nanoparticles are arising as one of the exciting tools for this purpose. Different materials can be used for the coating in nanotechnology e.g. Gold, Silver, PLGA, Chitosan, etc. Chitosan is preferred over Gold nanoparticles because it has unique properties such as less or negligible toxicity, being cost effective, biodegradability \& stability; high transfection efficiency, muco-adhesive properties and easy permeation into the cell wall ${ }^{9}$.

As the DNA is negatively charged, it interacts with the positively charged chitosan. Thus, Chitosan can form complexes with DNA easily. In the small intestines, it has the capacity to open up the tight junctions and protect the DNA from its degradation very effectively. Hence it serves as a good carrier for gene delivery ${ }^{10}$. Chitosan Nanoparticles have also shown to be having 2 times more immune enhancing activity as compared to hydrocortisone treated experimental animals ${ }^{11}$. Hence, the present study was planned to prepare, characterize and evaluate the antidiabetic efficacy of probiotic DNA loaded chitosan nanoparticles and its improvement through nanodelivery.

\section{MATERIAL AND METHODS}

Probiotic strain: Lactobacillus acidophilus NCDC343 (LA 343) was procured from NDRI, Karnal. The culture so obtained were given two revival cycles in de ManRogosa-Sharpe broth (MRS broth) at $37^{\circ} \mathrm{C}$ and maintained for further use.

Isolation of Genomic DNA from LA 343: For genomic DNA preparation, cells were grown in MRS broth containing $1.5 \%$ glycine to facilitate cell lysis. Genomic DNA was isolated ${ }^{12}$ and its quality was checked by agarose gel electrophoresis and quantity was determined spectrophotometerically.

Preparation of Chitosan Nanoparticles (CNP) and DNA loaded Chitosan Nanoparticles (DLCNP)

Purifiaction of Chitosan was performed according to ${ }^{13}$. Further, Chitosan and DNA loaded Chitosan Nanoparticles were prepared according to protocol given by Silva et $\mathrm{al}^{14}$ and Akbuga et $\mathrm{al}^{15}$ respectively.

\section{Characterization of DLCNP}

Characterization studies were performed through various experiments: Agarose gel electrophoresis (to determine complexed DNA), Loading efficiency and Loading capacity, SEM, TEM and Dynamic Light Scattering (to determine Size and Zeta potential) of Nanoparticles.

\section{Therapeutic potential of Probiotic DNA loaded Chitosan Nanoparticles against Diabetes}

\section{Induction of Experimental Diabetes ${ }^{16}$}

The Balb/c mice were divided into respective groups each of minimum six animals, housed individually in the departmental animal house and were exposed to $12 \mathrm{hr}$ cycle of light and dark. The experimental protocol was approved by Institutional Animal Ethical Committee (Registration No:107/99/CPCSEA/2014-21.Experiments were carried out as per the guidelines of committee for Purpose of Control and Supervision of Experiments on Animals (CPCSEA) Ministry of Environment and Forest, Government of India.

Experimental diabetes was induced by intraperitoneal (i.p.) ${ }^{17}$ administration of alloxan monohydrate in mice which had been subjected to overnight fasting. Total dose of alloxan $(150 \mathrm{mg} / \mathrm{kg} \mathrm{b}$. wt.) was administrated in three injections at intervals of $24 \mathrm{~h}(50 \mathrm{mg} / \mathrm{kg}$ b.wt.). Animals showing blood glucose level above $200 \mathrm{mg} / \mathrm{dL}$ (diabetic) were selected for further study.

\section{Experimental design}

Diabetic Balb/c mice were divided into 8 groups $(n=6)$. Group 1was Normal Control and groups 2-8 were made hyperglycemic by alloxan.

Group 1: Normal Control (Normal Diet) i.e. mice fed with basal feed.

Group 2: Hyperglycemic mice i.e. Untreated Negative Control fed with basal feed.

Group 3: Hyperglycemic mice dosed with Glybenclamide $10 \mathrm{mg} / \mathrm{kg}$ b.wt. on consecutive days.

Group 4: Hyperglycemic mice dosed with LA DNA at the rate of $75 \mu \mathrm{g}$ DNA per mouse.*

Group 5: Hyperglycemic mice dosed with DLCNP at the rate of $80 \mu \mathrm{g}$ DNA per mouse.*

Group 6: Hyperglycemic mice dosed with CNP.*

Group 7: Hyperglycemic mice were dosed with DLCNP, each dose containing $80 \mu \mathrm{g}$ DNA per mouse \& Glybenclamide (10mg/kg b.wt) * 
Group 8: Hyerglycemic mice dosed with LA DNA, each dose containing $75 \mu \mathrm{g}$ DNA per mouse \& Glybenclamide (10mg/kg b.wt) *

* 5 injections, intra-peritoneally ${ }^{17}$ at an interval of 6 days.

Collection of blood and determination of blood glucose

Blood of control \& experimental mice was collected from orbital sinus puncture using a heparinized capillary glass tube. The blood samples so collected were analyzed for blood glucose levels by glucose estimation kit (Gluco Dot Blood Glucose Monitoring System by Deep Meditech Pvt.Ltd.)

Experiment involved the acute \& sub-acute study. The acute study involved the estimation of blood glucose levels at $0,2,6$ and 12 hours after administration of LA 343, LA DNA, Standard market available drug Glybenclamide, CNP, DLCNP and combinations with all the doses given at one time. The sub-acute study involved the repeated administration of drug for 28 days at a prefixed time and blood glucose levels were estimated on days 7, 14, 21 and 28. The data were represented as mean blood glucose level and standard error mean (SEM).

The NBT reduction test was also performed to measure the neutrophil function ${ }^{18}$. Determination of NO in serum was performed by the measurement of stable decomposition product nitrite $\left(\mathrm{NO}_{2}\right)$ employing the Griess Reagent ${ }^{19}$.

\section{RESULTS}

\section{Characterization of DNA loaded Chitosan Nanoparticles}

The DLS experiment indicated that nanoparticles size ranging from to 276.5 to $351.7 \mathrm{~nm}$ were prepared with a positive zeta potential in between +12.6 to $+17.7 \mathrm{mV}$. Scanning Electron Microscopy revealed the shape \& the size of the Chitosan Nanoparticles. The particles observed were oval or spherical in shape and the range was between $200-800 \mathrm{~nm}$. Transmission Electron Microscopy showed the size of the Chitosan Nanoparticles ranging from 30 to $50 \mathrm{~nm}$. Loading capacity and loading efficiency was observed to be $0.18 \%$ was $97 \%$ respectively.

\section{Anti-Diabetic Activity}

\section{Acute treatment}

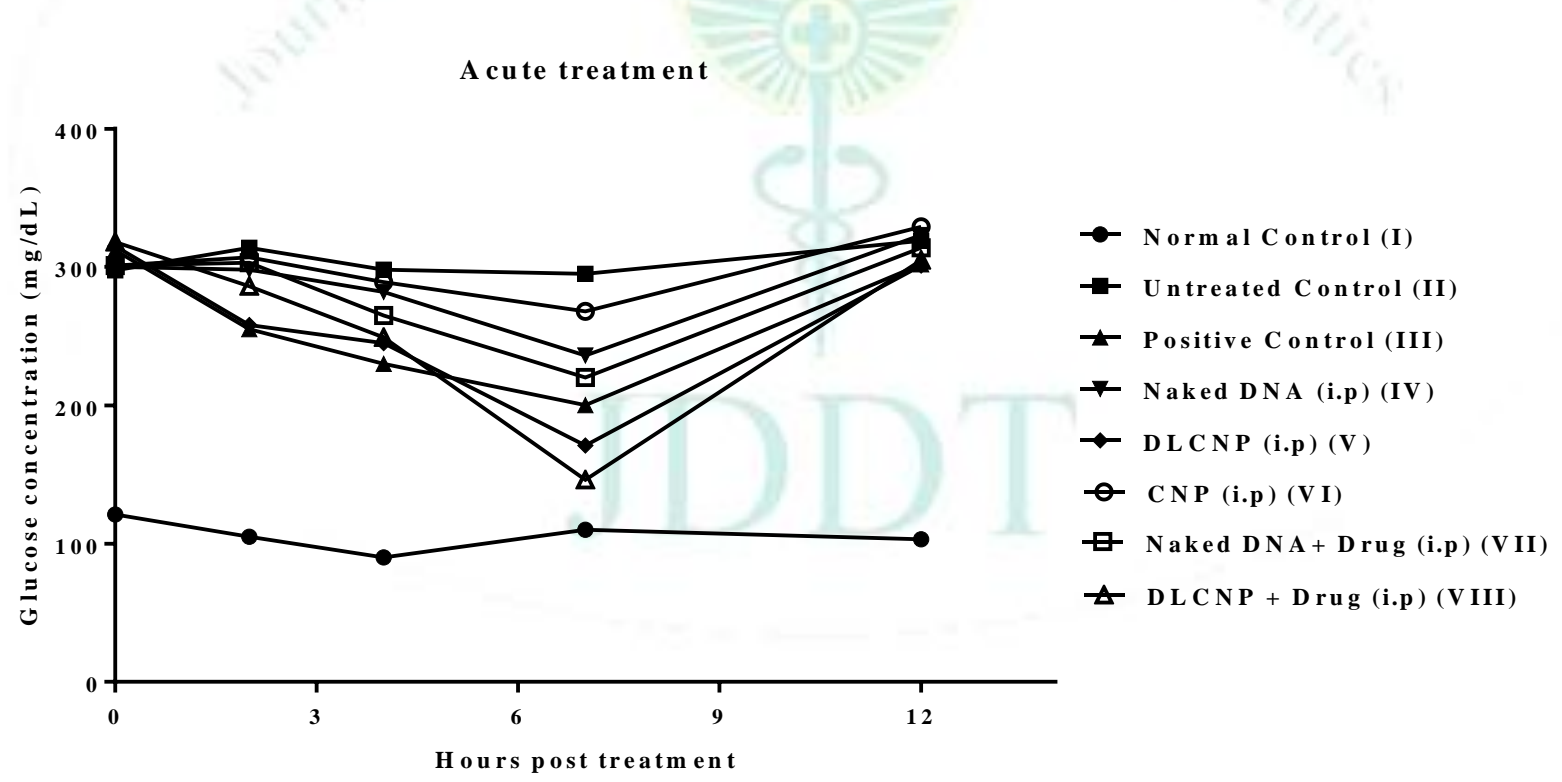

Figure 1: Effect of the sub-acute treatment of LA DNA, DLCNP, Drug Control \& their combinations [LA DNA \& Drug, DLCNP \& Drug] on Blood Glucose level in Alloxan induced diabetes in mice. Blood Glucose levels were assessed at regular intervals of hours $0,2,4,7,12$. Results are presented as mean \pm SEM ( $n=6)$.

Administration of the probiotic LA 343, CNP, DLCNP, Drug (Glybenclamide $10 \mathrm{mg} / \mathrm{kg}$ b.wt.) and combinations of (LA $343+$ Drug) and (DLCNP + Drug) significantly reduced blood glucose levels at 2,4,7,12 hours. The Untreated Control and CNP showed almost same glucose level from 0-12 hours. Between 6-8 hrs, LA DNA treated animals showed hypoglycemic effect which was $4 \%$ higher than the drug treated animals i.e. LA DNA and drug decreased glucose level by $35.34 \%$ and $31.09 \%$ respectively. DLCNP treated animals showed better hypoglycemic effect as compared to LA DNA treated group. Glucose level reduction in former was found to be $49.85 \%$ which was higher than that observed in later i.e. $35.34 \%$. When drug was used in combination with LA DNA and DLCNP, it was found that hypoglycemic effect in case of both groups, was higher than the animals treated with DLCNP and LA DNA alone i.e. (DLCNP + drug) showed hypoglycemic effect of $55.07 \%$ and (LA DNA + drug) showed $41.01 \%$. 


\section{Sub-acute treatment}

Sub-acute treatment

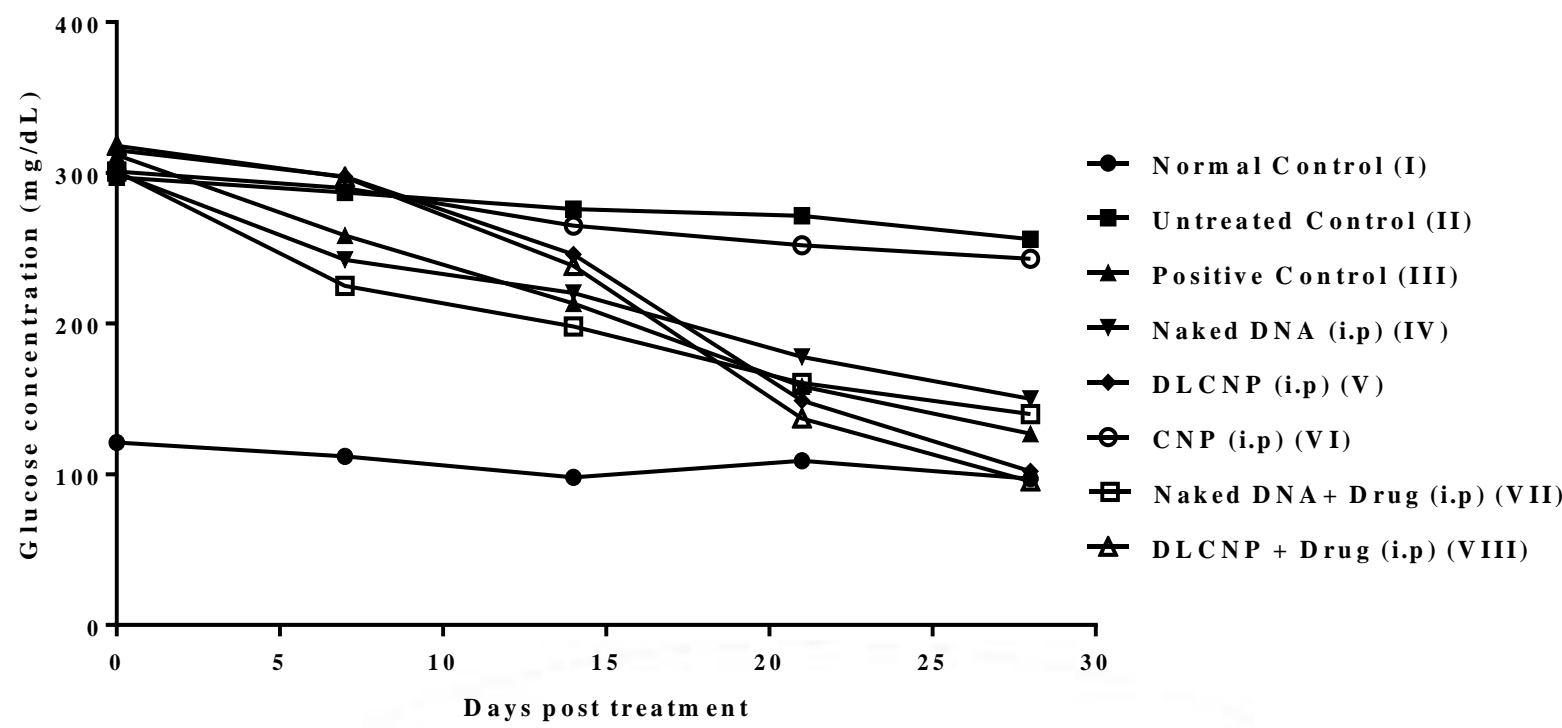

Figure 2: Effect of the sub-acute treatment of LA DNA, DLCNP, Drug Control \& their combinations [LA DNA \& Drug, DLCNP \& Drug] on Blood Glucose level in Alloxan induced diabetes in mice. Blood Glucose levels were assessed at regular intervals of days $0,7,14,21,28$. Results are presented as mean \pm SEM $(n=6)$.

Sub-acute administration of DNA LA343, Drug (Glybenclamide $10 \mathrm{mg} / \mathrm{kg}$ b.wt) and the combination as (LA $343+$ Drug) and (DLCNP + Drug) caused a significant reduction in the blood glucose levels as compared to control .In the Untreated Control, blood glucose level decreased slowly by low percentage of $24.15 \%$. The effect shown by untreated control as well as CNP was almost same. CNP also showed the hypoglycemic effect of $26.17 \%$ which was slightly higher than that of the untreated control. LA DNA gradually reduced blood glucose level by $52.05 \%$ within 28 days. The drug Glybenclamide (Positive Control), showed a hypoglycemic effect of $56.24 \%$ which was $4 \%$ higher than LA DNA treated group. The animals treated with DLCNP as well as its combination with drug showed less reduction in blood glucose level upto 14 days. After 15th day, faster reduction in the blood glucose was observed in both the test samples (DLCNP and DLCNP + drug) i.e. $62.17 \%$ and $66.07 \%$ respectively, till it reached normal blood glucose level at 28th day. Alone DLCNP was slightly less effective than its combination with drug.

\section{NBT reduction test in blood}

There was a parallel increase in glucose level and neutrophil's activity in the diabetic animals at the start of 28 day study. As, the glucose level decreased, due to therapeutic potential of test samples, neutrophil's activity also decreased and attained normal level at the end of $28^{\text {th }}$ day.

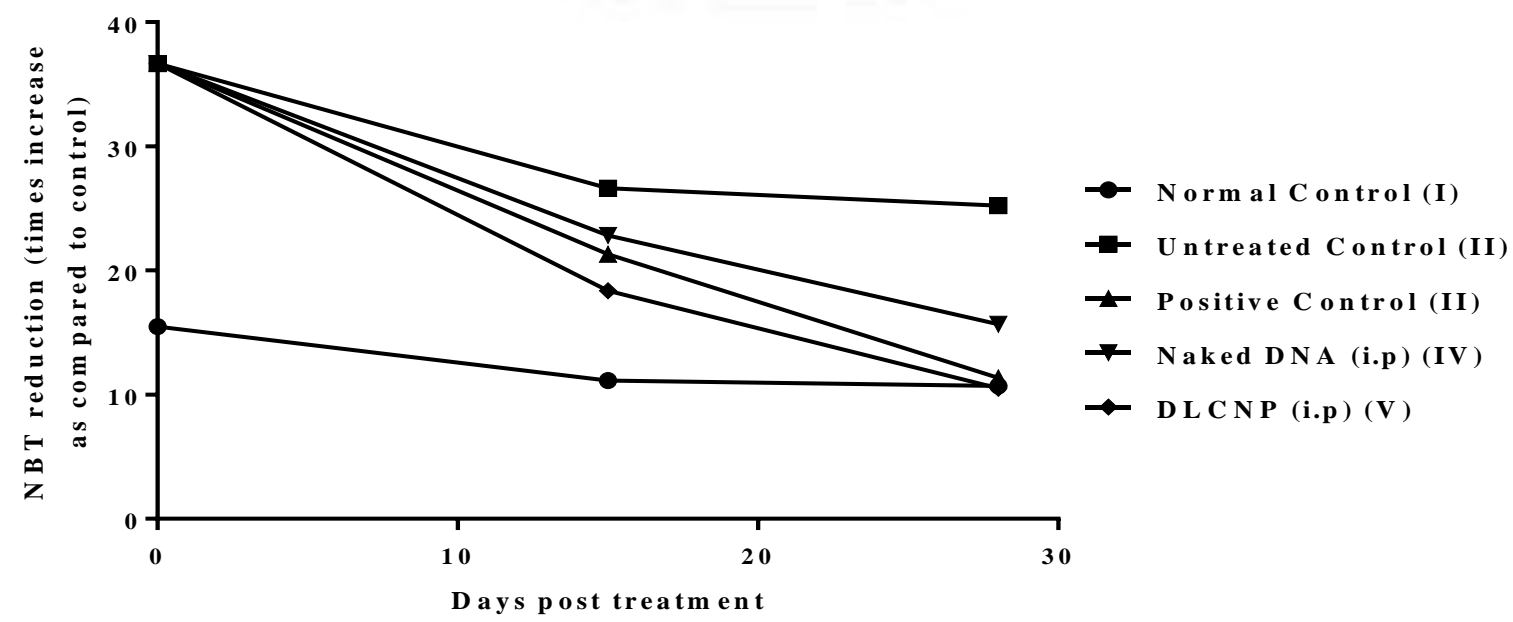

Figure 3: Effect of LA DNA, DLCNP, Drug Control \& their combinations [LA DNA \& Drug, DLCNP \& Drug] on NBT reduction in blood in Alloxan induced diabetes in mice. Blood was collected and assessed for NBT reduction on day 0,15 and 28. Results are represented as mean \pm SEM $(n=6)$. 
Disease control (hyperglycemic animals) showed the maximum Neutrophil's activity $(25.22 \%)$ as compared to the normal control (10.69\%) and all other (drug, LA DNA and DLCNP treated) groups. The drug Glybenclamide alone showed $21.3 \%$ neutrophil's activity within 20 days of treatment which further reduced to $11.35 \%$. Neutrophil's activity of $22.83 \%$ at $20^{\text {th }}$ day and $15.68 \%$ at $28^{\text {th }}$ day in LA DNA treated group was observed, both of which were slightly higher than drug treated group. DLCNP treated groups showed Neutrophil's activity with maximum increase of $18.37 \%$ at $20^{\text {th }}$ day and $10.51 \%$ at $28^{\text {th }}$ day as compared to the previous discussed groups.

\section{Determination of Serum Nitric Oxide concentration $(\mu \mathrm{g} / \mathrm{ml})$}

The drug treated group showed the maximum serum nitric oxide concentration of $49.31 \mu \mathrm{g} / \mathrm{ml}$, which was significantly higher than that observed in the normal control $3.58 \mu \mathrm{g} / \mathrm{ml}$. The Nitrite ions concentration in drug treated was $49.82 \mu \mathrm{g} / \mathrm{ml}$. The untreated control showed the concentration of $101.75 \mu \mathrm{g} / \mathrm{ml}$. DLCNP showed higher concentration than that of LA DNA. The DLCNP had concentration of $18.24 \mu \mathrm{g} / \mathrm{ml}$ and the LA DNA showed concentration of $46.31 \mu \mathrm{g} / \mathrm{ml}$.

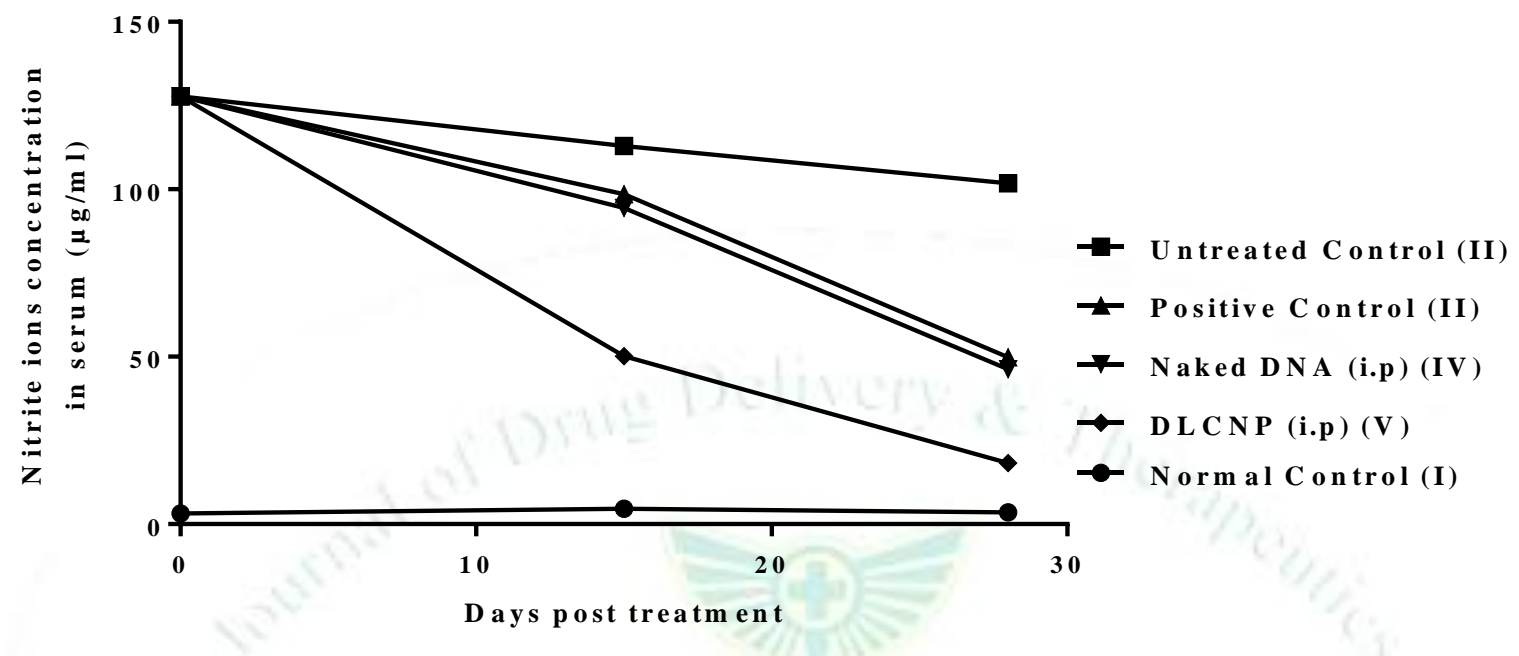

Figure 4: Effect of LA DNA, DLCNP, Drug Control \& their combinations [LA DNA \& Drug, DLCNP \& Drug] on Serum Nitrite Oxide concentration in Alloxan induced diabetes in mice. Blood was collected and serum was separated for determinations of serum nitric oxide concentration at day $0,15,28$. Results are represented as mean \pm SEM ( $n=6$ ).

\section{DISCUSSION}

Diabetes is a dreadful disease and the rise in the patients suffering from this disease raises an alarm. Diabetes can be treated by chemical based drugs, which do have side effects of allergies, nausea, skin irritation, itching, rashes, drowsiness and dry mouth etc. Hence, a need is felt to find the alternative therapeutic agents. Immune modulation is one of the safe modes of managing diseases. In the present project attempt has been made to apply the immune modulation properties of probiotic DNA as a cure for diabetes.

Immunomodulation using probiotics is like Lactobacillus, Bifidobacterium has already been documented 20,21, 22. Even the DNA of probiotics has immunomodulatory potential ${ }^{6,7,23}$. Since DNA is prone to nuclease degradation, hence it is protected by loading onto Nanoparticles. The Chitosan, Gold, PLGA, Silver etc. are highly compatible with DNA for its encapsulation. Because Chitosan is natural polymer, cost effective $\&$ is biodegradable ${ }^{10}$, it is preferred over all other polymers. It is also a hydrophilic carrier system.

The genomic DNA was isolated from LA 343 \& was subjected to in-vivo tests for anti-diabetic potential by Glucometer and it was characterized by employing the NBT, iNOS tests. The NBT (Nitroblue
Tetrazolium reduction) test is an indicator of the oxygen dependent bactericidal activity of phagocytosis ${ }^{24}$. NBT dye with low reduction potential when phagocytosed is reduced to formazon that can be measured spectrophotometrically ${ }^{25}$.

The possible mechanism behind this approach may be that the administration of the DNA loaded Chitosan Nanoparticles or LA 343 DNA showed a significant upregulation of Th-1 cytokine. T helper (Th) lymphocyte balance is crucial in regulating the appropriate cytokine response $\&$ hence remains as one of the targets for immunomodulation \& immune based therapies. Thus, the optimal immunotherapy should restore or maintain a well-balanced Th1 and Th2 response, suited to the immune challenge. Similar to the observations of the present study, earlier researchers have observed that Probiotics DNA stimulate the Th1 mediated immune response ${ }^{26}$. Thus present study was planned to load the probiotic DNA onto Chitosan Nanoparticles \& evaluate the anti-diabetic potential. Therefore, five groups of the animals were set up as follows and were treated as: LA DNA, DLCNP, CNP, LA DNA + Drug and DLCNP + Drug. The administration of DLCNP in alloxan induced diabetic animals showed better hypoglycemic effect as indicated in acute ( 0 to $12 \mathrm{hrs}$ ) as well as sub-acute study ( 0 to 28 
days). The animals treated with DLCNP as well as its combination with drug showed less reduction in blood glucose level than LA DNA and its combination with drug, upto 14 days; but faster reduction in the blood glucose was observed after $15^{\text {th }}$ day in both the former groups.

The NBT test (Nitroblue Tetrazolium Reduction) test is an indicator of the respiratory burst and the nitric oxide test indicates the non-oxidative mechanism of killing of microbes. NBT is an indirect marker of the measure the neutrophil function. Whenever a particle is ingested by a phagocyte,a respiratory burst is induced. The assay was based on the reaction that addition of yellow colored NBT dye to neutrophils results in the formation of complex which can be phagocytosed by neutrophils. The yellow colored NBT was reduced to the blue colored formazone which can be extracted in Dioxan. Griess reaction involved the formation of a chromophore during the reaction of nitric oxide $\left(\mathrm{NO}_{2}\right)$ with sulphanilamide and heterocyclic amine of $\mathrm{N}$-(1-napthyl) ethylenediamine (Griess reagent) under conditions of low $\mathrm{pH}$. During this reaction acidified nitrite undergoes diazotization with sulphanilamide to form diazonium salt. This diazonium salt then coupled to $\mathrm{N}$-(1-napthyl) ethylenediamine to form magenta colored compound with a characteristic absorption spectrum.

Underlying mechanism behind this approach is proposed to be because of the unmethylated $\mathrm{CpG}$ motifs. It was noted that the genomes of the bacterial and viral DNA contain much higher frequency of unmethylatedCp $\mathrm{G}$ dinucleotides than those of vertebrates. The DNA interacts with the ligand polycation Chitosan and forms the DNA-Chitosan complex which is endocytosed and

\section{REFERENCES}

1. Kaveeshwar SA, Cornwall J. The current state of diabetes mellitus in India. Australas Med J. 2014; 7(1):45-48.

2. Ryan G, Briscoe TA, Lynette L. Review of pramlintide as adjunctive therapy in treatment of type 1 and type 2 diabetes. Drug Des Devel Ther. 2009; 2:203-214.

3. McFarland LV. Meta-analysis of probiotics for the prevention of antibiotic associated diarrhoea and the treatment of Clostridium difficile disease. Am J Gastroentrol. 2006; 101(4):812-822.

4. McCabe LR, Irwin R, Schaefer L, Britton RA. Probiotic use decreases intestinal inflammation and increases bone density in healthy male but not female mice. J Cell Physiol. 2013; 228(8):1793-1798.

5. Krammer HJ, Kamper H, Von Banau R, Zieseniss E, Stange C, Schlieger F, Clever I, Schulae J. Probiotic drug therapy with E.coli strain Nissle $1917(\mathrm{EcN})$ : results of a prospective study of the secords of 3807 patients. Z Gastroentrol. 2005; 44:651-656.

6. Randhawa MK, Bhatia $\mathrm{A}$, Ali SA, Balgir PP. In vivo comparison of probiotic bacteria's with their DNA: As augmenter of immune efficacy, Adv Appl Sci Res. 2012; 3:826-832.

7. Ghadimi D, Holst RF, de Vrese M, Winkler P, Heller KJ, Schrezenmeir J. Effects of Probiotic bacteria and their genomic DNA on TH1/TH2- cytokine production by peripheral blood mononuclear cells (PMBCs) of healthy and allergic subjects. Immunobiology. 2008; 213:677-692.

8. Krieg AM. Cp G motifs in Bacterial DNA and their immune effects. Annu Rev Immunol. 2002; 20:709-760. further binds to receptors like TOL like receptor $9 \&$ interacts with the cell membrane inside the cell. The endosome formed releases its components inside the cell that are taken up by nucleus through trafficking and leads to the activation of various immune cells \& production of cytokines. The balance of Th1 \& Th2 cytokines plays role in enhancing the immunomodulatory potential \& treating various diseases. ${ }^{27}$

The combination of the drug Glybenclamide and DNA of LA 343 showed significantly higher hypoglycemic effect of as compared to the drug Glybenclamide alone. Hence, the results show that the interaction between the probiotic DNA and the Chitosan Nanoparticles showed the maximum anti-diabetic potential in the host body system. Moreover studies have shown that probiotics reduced the blood glucose levels 28,29 and there is a co-relation between blood glucose level and immune-modulation ${ }^{30}$. Hence, our study highlights that to get immune effects, it is not necessary to give whole bacteriall cell in the diabetic host instead genomic DNA of probiotic cell can also be used as a safe anti-diabetic agent. Moreover, the results indicate that probiotic genomic DNA loaded onto nanoparticles enhance the anti-diabetic potential of DNA.

\section{Abbreviations}

CpG-ODNs: Oligodeoxynucleotides containing CpG motifs LA 343: Lactobacillus acidophilus NCDC343

LA DNA: Genomic DNA isolated from LA 343

CNP: Unloaded Chitosan Nanoparticles

DLCNP: Probiotic DNA loaded Chitosan Nanoparticles

NBT: Nitroblue Tetrazolium reduction test

9. Tiyaboonchai W. Chitosan Nanoparticles: A Promising System for Drug Delivery. Naresuan Univ J. 2003; 11(3):5166.

10. Rajalakshmi R, Indira MY, Aruna U, Vinesha V, Rupangada V, Krishna moorthy SB. Chitosan Nanoparticles - An Emerging Trend In Nanotechnology. Int J Drug Delivery, 2014; 6:204-229

11. Bhatia A, Shard P, Chopra D, Mishra T. Chitosan nanoparticles as Carrier of Immunorestoratory plant extract: synthesis, characterization and Immunorestoratory efficacy. Int J Drug Delivery. 2011; 3:381-385.

12. Atashpaz S, Khani S, Barzegari A, Barar J, Vahed SZ Azarbaijani R, Omidi YA Robust Universal Method for Extraction of Genomic DNA from Bacterial Species. Microbiology. 2010; 79 (4):538-542.

13. Chew JL, Wolfowicz CB, Mao HQ, Leong KW, Chuaa KY .Chitosan nanoparticles containing plasmid DNA encoding house dust mite allergen, Der $\mathrm{p} 1$ for oral vaccination in mice. Vaccine. 2003; 21:2720-2729.

14. Silva VJDD. Preparation and characterization of chitosan nanoparticles for gene delivery. Technico Lisboa. 2013; 1-10.

15. Akbuga J, Turan SO, Erdogan N. Plasmid-DNA loaded chitosan microspheres for in vitro IL-2 expression. European J Pharm Biopharmaceutics. 2004; 58:501-507.

16. Ozbek H, Ceylan E, Kara M, Ozgokce F, Koyuncu M. Hypoglycemic effect of Rheumribes roots in alloxan induced diabetic and normal mice. Scand J Lab Anim Sci. 2004; 31:113-115.

17. Gao X, Huang L. Potentiation of cationic liposome-mediated gene delivery by polycations. Biochemistry. 1996; 35:10271036 . 
18. Hudson L, Hay FC. A handbook of practical immunology (3rd ed.), Oxford: Blackwell scientific publication, London. 1989.

19. Mathew G, Glenda J, Jack L .Quantitaion of nitrite and nitrate ions in extracellular fluids. Enzymology. 1996; 268:237-246.

20. Matsuzaki T, Chin J. Modulating immune responses with probiotic bacteria. Immunol. Cell Biol. 2000; 78(1):67-73.

21. Bhatia A, Pawan R. Therapeutic effect of probiotic immune response and hypercholesteremia: an experimental study. Res J Biotech. 2007; 2 (3):43-46.

22. Kwon K. Generation of regulatory dendritic cells and CD4+ Foxp3+ $\mathrm{T}$ cells by probiotics administration suppresses immune disorders. PNAS. 2010; 107(5): 2159-2164.

23. Bhatia A, Kaur M, Kaur H. Comparison of Immunomodulatory Activity of Probiotic Bacteria and their DNA: A Study Conducted with $L$. acidophilus NCDC343 \& $L$. casei Isolated from Yakult. Int J Pharm Res Scholars. 2015; $4(1)$

24. Hellum, K.B. Nitroblue Tetrazolium test in bacterial and viral infections. Scand J Infect Dis. 1977; 9:269-276.

25. Szczylik C, Gornas P, Carewicz R. NBT reduction test methods and practical use. Diagn Lab. 1979; 1:35-40.
26. Klinman DM, Yi A, Beaucage SL, Conover J, Krieg AM. $\mathrm{CpG}$ motifs expressed by bacterial DNA rapidly induce lymphocytes to secrete IL-6, IL-12 and IFNg. Proc Natl Acad Sci. 1996; 93:2879-2883.

27. Chuang L, Wu KG, Pai C, Hsieh PS, Tsai JJ, Yen JH, Lin MY. Heat-killed cells of lactobacilli skew the immune response towards $\mathrm{T}$ helper 1 polarization in mouse splenocytes and dendritic cell-treated T cells. J Agr Food Chem. 2007; 55(26):11080-11086.

28. Tabuchi M, Ozaki M, Tamura A, Yamada N, Ishida T, Hosoda M, Hosono A. Antidiabetic effect of Lactobacillus GG in streptozotocin induced diabetic rats. Biosci Biotechnol Biochem. 2003; 67(6):1421-4.

29. Yadav, H., Jain, S. and Sinha, P.R.2007.Antidiabetic effect of probiotic dahi containing Lactobacillus acidophilus and Lactobacillus casei in high fructose fed rats. Nutr. 23(1):62-8.

30. Bhatia A, Mishra T. Hypoglycemic activity of Ziziphus mauritiana aqueous ethanol seed extract in alloxan-induced diabetic mice. Pharma Biol. 2010; 48 (6):604-610. 